\title{
CORRIGENDUM
}

\section{The effect of 4-week chilli supplementation on metabolic and arterial function in humans}

KDK Ahuja, IK Robertson, DP Geraghty and MJ Ball

European Journal of Clinical Nutrition (2007) 61, 442. doi:10.1038/sj.ejcn.1602544

Correction to: European Journal of Clinical Nutrition (2007) 00, 000-000. doi:10.1038/sj.ejcn.1602517

In this article published online 23/08/06 and in this issue, the authors have identified an error on page 7 , line 4 , left-hand column. The line should read 'provided a mean of only $0.44 \mathrm{mg} / \mathrm{kg}$ body weight per day'.

The authors apologize for any confusion caused. 